JoUrnal OF INTER-American Studies - Vol. VII, No. 2

\title{
CONTENTS
}

April, 1965

\section{The Forgiven FaulKner}

Hodding Carter

Cotton and Cattle in the Pacific Lowlands of Central America James J. Parsons . . . . . . . . . . . . . . . . . . . . 149

The United States Air Force and Latin American Research David Bushnell .........................161

Quelques Poetes Haitiens de la Jeune Génération

Maurice A. Lubin . . . . . . . . . . . . . . . . . . . . 179

GOVERNMENT AND DEVELOPMENT:

Managerial Attitudes in Latin America

Albert Lauterbach .........................201

Social Backgrounds of the Bogotá Entrepreneur

Aaron Lipman ...........................227

Ecuador: Síntesis Nacional

Eduardo Santos Camposano ....................237

The Christian Democrats of Venezuela

Franklin Tugwell ...................245

One America - Two Cultures

William J. Kilgore ......................269 